ARTICLE

Received 8 Mar 2016 | Accepted 2 Sep 2016 | Published 7 Oct 2016

\title{
Libraries for the future: the role of IT utilities in the transformation of academic libraries
}

Elizabeth Tait ${ }^{1}$, Konstantina Martzoukou ${ }^{1}$ and Peter Reid ${ }^{1}$

\begin{abstract}
This article presents an evaluation of the role of IT utilities in the transformation of academic library services. It begins with a brief overview of the historical development of academic libraries followed by a discussion of current challenges and opportunities for academic libraries. It then offers reflections on the changing role and focus of academic libraries, evident, for example, via the reduction of physical book stock and through an increased focus on collaborative learning spaces. The article also discusses examples of innovative technological developments for learning, data management and the impact of these on the academic library sector, including the need for library staff to develop new skills and roles such as "embedded" librarian roles. The article concludes with reflections on future developments and the role of IT Utilities.
\end{abstract}

${ }^{1}$ iSchool, Robert Gordon University, Aberdeen, UK Correspondence (email: e.j.tait@rgu.ac.uk) 


\section{Introduction}

he notion that technologies are as a force of "disruptive innovation" in the library sector has been discussed extensively in the academic literature and the wider press. Furthermore, the challenges and opportunities brought about by technological developments such as e-books and broadband Internet access in households with the added pressures from cuts to public services are well known. Many of these developments have called into question what the role of physical libraries is (or should be) in the twenty-first century. For example, the concept of the "library without walls" (Weiss, 2004) has been mooted whereby patrons can utilize the services of the library irrespective of physical location (Bilandzic and Johnson, 2013). The dire predictions of the death of the physical library has not come to pass, however, and while visits to public libraries have declined, visits to academic libraries have remained steady. The increasing student numbers at higher education institutions means that the footfall in academic libraries has actually increased although user behaviour, including borrowing patterns have changed significantly over the last 10 years (SCONUL, 2015). There has also been a shift in the user demographics of academic libraries and changes in the way that patrons engage with the physical space. The roles of institutions such as libraries, museums and archives are evolving beyond being primarily about collecting, storing and disseminating information and towards becoming spaces of social learning and spaces where knowledge is created and shared (Paulus, 2011). This is evident when we look at high profile examples of innovative new library designs, which tend to combine modern architecture and design with a more community and collaborative approach to service delivery (Arts Council England, 2013).

These issues were explored in depth in a working group called "Libraries of the Future" organized by the IT as a Utility Research Councils UK (RCUK) Digital Economy Network between 2013 and 2015. The network took a broad definition of IT Utilities and had a remit to investigate "... simple, usable and safe IT provision from smart services, surroundings and information stores." (ITaaU, n.d). A series of participative workshops were held bringing together an interdisciplinary range of: academics, library and information professionals, industry practitioners and other stakeholders to discuss the challenges and opportunities of IT Utilities for libraries. The aim of the group was to inform the research agenda and make recommendations for policy and professional practice, including the education of future information professionals. This article presents an analysis and reflection of the key topics discussed and debated within the group. The specific objectives of the paper are: to contextualize the debates around IT Utilities within the broader context and historical development of the academic library service; to present an overview of some of the key technological developments relevant for the sector; to reflect and critically discuss the impact of these on the role and professional practices of academic library staff and, finally, to consider what the future of academic libraries and academic librarianship will be.

\section{The development of the academic library}

Academic libraries have a rich history and heritage and have always played an important role in academic research, teaching and scholarly communication (Fjällbrant, 1997). Academic libraries have evolved and developed alongside the higher education institutions that they are part of and are characterized as being resilient institutions that have demonstrated the capacity to adapt to changing social, political and technical forces (Gilmour and Sapp, 2002; Weiner, 2005). There are many different models of academic library from vast world renowned collections such as those to be found at institutions like Yale, Harvard, Cambridge and elsewhere to distributed, federal campuses in more recently established institutions such as the University of the West Indies. It is interesting to note at a time when much discussion is focussed around the reduction of physical stock in libraries that the earliest university libraries did not have large collections and tended to rely on donations of manuscripts and other artefacts with famous collections, such as the Bodleian at the University of Oxford having a core of bequeathed materials at its heart.

Academic library collections started expanding in the late nineteenth and early twentieth centuries, and an element of competitiveness began to emerge between them in terms of the size and value of their collections (Weiner, 2005). In the post-war period there was a vast increase in scholarly output and this, combined with the development of early computing technologies in the 1970s led to new systems for the storage, cataloguing and retrieval of information (Gilmour and Sapp, 2002). While these developments helped library staff to develop new services and cope with the surge in information, there were already concerns that digital services and automation would lead to the extinction of libraries and that the role of librarians could be redundant and there was recognition that the nature of academic librarianship needed to change. By the mid 1980s there was a recognition that: "The entire enterprise of scholarly communication was evolving in ways that tended to de-institutionalize information. Libraries could not and should not expect to retain a monopoly over information" (Gilmour and Sapp, 2002: 565). However, such perspectives have sometimes failed to take enough account of the fact that libraries have evolved continually and the role of the librarian has also developed in line with the process of change.

As scholarly publication and access has shifted even further towards electronic services academic libraries were forced to adapt further in order to demonstrate the "value added" services that they could deliver (Gilmour and Sapp, 2003). The management of electronic services in the academic environmentincluding organization, dissemination, curation and the provision of those services is not without its challenges, but these are issues that library staff should play a central role in solving. As in the past with other innovations, digital developments afford opportunities for academic library staff to create new roles and new ways of delivering services for users. One obvious area is in the creation of seamless information architecture and knowledge organization structures that facilitate easy access and retrieval from online tools. This technical infrastructure is important in assisting users to understand the integrity of scholarly publication and information in an otherwise unregulated and unmediated digital environment.

Technical developments are not the only factor that has impacted on academic library service delivery. The evolving shape of pedagogy in higher education has been one of the key reasons for the change in shape of academic libraries. Students now study in many different ways and the role which the library plays in this is evident with a shift away from places which were traditionally silent study areas to become flexible and dynamic spaces suited to social and group learning. Blended learning, drawing on both the physical and virtual spaces have compelled the reconfiguring of academic libraries in much the same way as technological developments have changed the role of the academic librarian. The Philological Library at the Freie Universität in Berlin, the Sir Duncan Rice Library at the University of Aberdeen or the Hive at the University of Worcester are all recent examples of revolutionary approaches to the design of the academic library which reflect the changing nature of their use. 
However, despite this period of growth and investment in new systems and services, many higher education library services suffered from budget cuts and resulting pressures on service delivery although the figures vary between countries and institutions (Nicholas et al., 2010). Libraries have been forced to make efficiency savings-some also assisted by technologiessuch as self-service machines and electronic rather than physical subscription to periodicals (RIN, 2010). Continued financial pressures combined with expectations that academic libraries will take on additional responsibilities such as research data management and open access requirements mean that this is a challenging time for academic libraries. The article will go on to explore these challenges and opportunities in more detail.

\section{The library role in open access and research data management}

One of the most significant recent developments in scholarly academic publication is open access. The movement for open access publications has been growing for some time in response to the high fees for journal article, access which meant that publicly funded research was only accessible to a small number of (usually) academic readers that limited public access and was also considered a barrier to social, cultural, technical and economic benefits of research. Open access is a global phenomenon; Kingsley and Kennan (2015) identified initiatives in a range of countries including the United States, where open access has been a mandate for recipients of funding from the National Institutes of Health since 2007. There are also open access expectations for recipients of Horizon 2020 EU grant awards and similar mandates in countries such as Australia and Japan. In 2012, a Working Group on Expanding Access to Published Research Findings produced the "Finch Report" on open access and shortly after this the RCUK adopted the recommendations for open access publications requiring that all work funded with public money should be made available via open access. In addition the Higher Education Funding Council for England (HEFCE) announced that research submitted to the next Research Excellence Framework (REF) should also be open access (Hall, 2012). The HEFCE (2015) policy issued in July 2015 states that "to be eligible for submission to the post-2014 REF, authors' outputs must have been deposited in an institutional or subject repository".

In addition to the requirements for open access to publications, there are also regulations surrounding the management of academic data. Academic data is produced and shared in large volumes and represents a significant investment in public money, as well as being valuable resources for the advancement of knowledge. It is understandable then that research data management is a major preoccupation within the academic and research sectors "...from its entry to the research cycle through to the dissemination and archiving of valuable results" (Whyte and Tedds, 2011). Requirements for institutions to put into place policies for research data management have been driven by a number of factors, including the increasing prominence of data intensive research and also by requirements from journals and funding bodies to collect and store data, and to make it available for other researchers to use. In the United Kingdom, funding councils have introduced requirements for academic institutions to have formal processes in place for curating data generated by publicly funded research projects (RCUK, 2015). Research data is a resource that demands sophisticated approaches to curation and management (as Joint Information Services Commission (JISC) has identified in its Managing Research Data Programme 20112013). There is an increasing pressure for institutions (particularly in the academic sector) to exploit research data more fully, particularly when it has been generated through the use of public funding (Cox and Pinfield, 2014).

These new policies and guidelines have had significant implications for research communication, publishers and academics and, of particular relevance for this paper, for libraries. Responsibility for the development and management of institutional repositories has largely been allocated to university libraries as an extension of their traditional function for the storage and dissemination of academic work (Swan, 2011). The development of repositories can be viewed as being jointly enabled by the funding mandates and also by technical developments, including open source repository solutions that has made the initiatives possible. Many institutions already had repositories in place before the mandate with a large number being developed with support and funding from the JISC in a series of development programmes (Jacobs et al., 2008).

Collection management in academic libraries has been further complicated by changing business models of academic publishing. For example, commercial publishers are increasingly turning to Article Processing Charges for open access journals. Academic library staff need to be able to navigate the heterogeneous business approaches and to engage and consult with academics and university managers, and determine how resources should be allocated (Arte and Cassella, 2014). Houghton and Oppenheim (2010) conducted a cost-benefit analysis of new publishing models facilitated by open access repositories in a JISC EI-ASPM project. This included examination of "overlay journals" where authors self-archive in repositories and these are then indexed and used as the foundation for overlay services such as peer-review and quality control (Houghton and Oppenheim, 2010). The authors concluded that “...more open access would have substantial net benefits in the longer term, and while net benefits may be lower during a transitional period, they are likely to be positive for both open access publishing and self-archiving alternatives (that is, Gold OA) and for parallel subscription publishing and self-archiving (that is, Green OA)." (Houghton and Oppenheim, 2010: 13). A concomitant development to open access repositories are Current Research Information Systems (CRIS) that are usually used to support institutional research information management with a particular focus on funding and projects (De Castro et al., 2014). These are separate but clearly related activities within academic research and many systems allow for CRIS/IR interoperability based on systematic metadata exchange to facilitate reporting and monitoring of research performance, and impact to funders, inter-institutional collaboration and other stakeholders (De Castro et al., 2014).

As well as the technical and logistical challenges of curating academic data and publications, there are also potential challenges for library staff of engaging researchers and overcoming some long held concerns about keeping control of data, concerns about intellectual property (especially if the research has potential for commercialization) or ethical concerns from researchers about the potential for sensitive information to become public or for research participants' anonymity to be compromised (Cox and Pinfield, 2014). The additional responsibilities of open access and data management are also coming at a time where funding and resources are under pressure for academic libraries. Staffing levels (in particular for professionally qualified librarians) are being reduced in many institutions and there are limited budgets for skills and training of staff. Institutions, such as the Digital Curation Centre provide crossinstitutional support and provide resources such as DMPonline to assist researchers in making data management plans. Further national initiatives have been developed such as the Jisc Research Data Registry and Discovery service and the Australian National 
Data Services have been developed to aid the discovery and reuse of research data (Davidson et al., 2014) and there are knowledge transfer networks between institutions, but some still question whether libraries have the capacity and skills to take on these new responsibilities.

\section{Library IT utilities for a changing pedagogical environment}

Twenty-first century academic libraries extend beyond the walls of their individual institutions to online open access information spaces, dealing with intelligent Internet sharing tools and online social communication, and networking technologies. Academic library staff should also be in a position to support diverse and international university learning communities, and understand and be responsive to the needs of all international students that use the library, ensuring that they receive an equivalent high quality service. In a fast growing international education environment there are new challenges created for academic library staff that call for an investment in skills development and continuous improvements on the basis of delivering effective, meaningful, interactive, flexible and culturally aware library services and programmes. There has been a move towards a more market-oriented approach to HE institutions that is reflected in great competition for recruitment of International students. In England and Wales (but notably not in Scotland) this is compounded by the removal of student recruitment caps and increasing tuition fees. Student satisfaction metrics are increasingly being collected, through mechanisms, such as the National Student Survey that impact on university league tables and have a direct impact on services provided. All parts of universities, including libraries have to respond to this customer-focussed approach and are in competition with each other for resources. Users have increased expectations of ubiquitous digital access "on demand" and many university libraries also have to support a growing population of distance learning students who may never attend campus (Creed-Dikeogu and Clark, 2013). Online learning and teaching (including MOOCs) requires a significant movement from traditional on campus modes of library delivery, support, and advice that is appropriate to the needs of distancelearning students, whether overseas or home students, and their diverse learning environments, expectations and requirements.

These developments require a culture of openness and sharing that challenges the traditional stereotype of library work as controlled, mediated information access and a more user-centred approach to meet the needs and requirements of an increasingly global library community. Libraries have responded to this by developing new methodologies for analysing user experiences (sometimes known as "UX research") that include qualitative ethnographic studies to better understand how patrons use library spaces (Datig, 2015). Observational studies by researchers such as Applegate (2009) have demonstrated that while students are using academic library spaces in different ways than before (for example, bringing their own laptops), that the library continues to be a key space for learning and scholarly activities within academic institutions and that effective libraries must be responsive to these needs. This replaces traditional models of uni-directional services as library staff and the communities they serve can be co-producers of library services (Berube, 2011: 30). For example, the library corporate website that traditionally included mainly static, directional, descriptive information to internal and external services provided by the library has now evolved into a more dynamic online space with the utilization of Web 2.0 tools, such as RSS feeds, social networking sites such as Facebook, audio and video podcasting and blogging; these act as easily accessible communication tools for users that keep them in touch with the library and enable the development of a participation framework for further sharing, collaborating and creating of new information.

With the transformational impact of IT Utilities libraries are thus increasingly moving towards a model that has shifted power from provider to user. For example, modern libraries are now embracing Web-scale discovery systems that enable the use of a single central index and search interface that allows searching across local library services, subscriptions collections as well as open access resources. This move mirrors the working model of major commercial database vendors, such as EBSCO, Ex Libris, Serial Solutions Summon and OCLC's WorldCat Local, who all offer discovery services that harvest information from a wide variety of publishers and open-access repositories. Some of these services allow features that support user tagging, user ratings and reviews, integration with personal accounts, and sharing with external sites, such as Facebook. Electronic catalogue technology now offers functionality and services which improve information discovery via the Social Web and support searching various open sources including Web search engines and allowing user comments, reviews, ratings, added subjects and keywords, which provide user input to library collections and services.

Technology has transformed additional services traditionally offered by libraries. For instance, online reading lists have been widely adopted by academic libraries as an effective means for creating, editing, personalizing, updating and integrating reading lists into online learning and teaching material, helping students to connect directly and seamlessly with the reading resources of their courses. In addition, academic library staff can readily address the needs of academics for ordering books, as well as their training needs for managing and maintaining their reading lists. This undoubtedly also creates new needs. A study of Talis Aspire and reading lists, for example, highlighted the need to improve communication between faculty and library staff needs (Cameron and Siddall, 2015) drawing from earlier research that identified an "asymmetrical disconnection" (Christiansen et al., 2004: 18) between academics and library staff with the former having little understanding of the responsibilities and roles of library staff in setting up and managing these lists.

Another example is the domain of eBooks, which is a growing part of the online services offered by academic libraries, yet there are still some important challenges and difficulties encountered in the selection, licencing, acquisition, management and promotion of these materials. These include dealing with the lack of uniformity and restrictive terms in licencing provision, the diversity of different ways they are made available (platforms, formats and software) and the different expectations of libraries, faculties and e-book providers. Traditional models of book lending followed in the physical library cannot be transferred to the digital environment and students' reading habits and expectations of access create difficulties for libraries to replicate equivalent instant and unrestricted reading experiences. Yet, beyond the challenges encountered, this is another area that library staff are given an opportunity to define and assert new and significant roles. Walters (2013) for instance, asserts that academic library staff are well-positioned to offer guidance to eBook vendors for the development of meaningful e-book licences and usable platforms for the academic environment and this implies that they "have an important role to play in shaping the e-book environment, especially since publishers have yet to agree on the best ways of providing and marketing e-books to academic libraries" (201).

\section{Social media and mobile devices}

Other areas of technological change for academic libraries include the use of mobile technologies and particular "smart" devices of 
different types, utilized by both students and faculty, such as iPads, Kindles, smartphones, or other mobile devices. In an information world of instant solvability of information problems with access to easy to use web search engines, social media and mobile technologies, and $\mathrm{Wi}-\mathrm{Fi}$ access to the Internet, the expectation is that it is possible to find information for immediate use at anytime and anywhere with less need to be educated how to develop information skills and use quality-controlled information sources (Wilder, 2005). The pressure for libraries to keep up with not only new technologies but more profoundly with these expectations is immense. According to a survey of almost 35,000 8 - to 16-year-olds, conducted by the National Literary Trust, young people are now much more likely to prefer to read on a computer screen rather than a printed book or magazine (National Literacy Trust, 2013), which makes sense considering that 85 per cent have a mobile phone while only 73 per cent own books (Clark and Hawkins, 2010). Considering that these are the university students of tomorrow, it is clear that priorities for libraries are changing as students have preference for accessing information using different methods and approaches, which signify a change in reading habits.

Libraries are some of the most active users of social media, making services more participatory, embracing openness and reaching a wider audience, allowing them to communicate and engage with its community in dialogue, which informs and helps develop its products and services, and how it operates. Social media tools can be used within this context for a number of different purposes. For example, services can create a strong presence and a modern image that could appeal to less frequent users of the physical buildings such as teenagers. Libraries can develop services online (for example, book discussion groups using blogs and wikis) and provide services and product updates on social media tools such as Twitter. Web 2.0 can also offer costeffective solutions for the production of promotional and marketing material about services and materials available using services such as YouTube. Web 2.0 helps raise awareness of services overcoming barriers associated with traditional methods of publishing (for example, by overcoming delays associated with posting information on the website of the wider organization, a process that is often controlled by the IT department). Social media can also be used as a means of networking, communication and sharing of ideas with other professional organizations and colleagues, who work in different contexts, allowing the wide spread of ideas and creating expanding international networks (Chu and $\mathrm{Du}, 2013$ ).

Although the primary utility of social media is centred on marketing and awareness services, they can also be used as tools for information literacy training. For example, libraries can help their users develop information seeking competence in a number of ways using online social media. They can develop database instructional videos that aid navigation and information searching approaches on complex information retrieval environments that could be uploaded on services, such as YouTube and Vimeo; (more information on these is given below); they can create interactive reference services such as FAQs and chat widgets using Springshare's LibAnswers that have been used to great effect (Stevens, 2013).

Social media can also be utilized independently by users as tools for information searching and discovery. Although search engine use is one of the most popular search approaches to Web information seeking, an alternative way is to use online social media by posing questions to key individuals and groups online, and browsing across online social networks. When online social media are used for finding information, this has been broadly referred to as social search. This technique may involve online social media directly or via the initial use of search engines that index social media webpages (for example, public Twitter posts, social tagging tools such as Delicious). Social search may involve browsing or active requests for help from the searcher to other people. In a study of social search behaviour comparing the experience of searchers who asked a questions to a group of people they knew personally (by means of a social network status message update) and the experience of searching for the same information with a Web search engine, Morris et al. (2010) surveyed Facebook and Twitter users about situations in which they used a status message to ask questions of their social networks. Benefits of asking a social network included opiniontype answers, and that their social network knew additional context about them. Social networks seem particularly useful for subjective questions. People considered the results from their social network highly trustworthy and favoured the delivery of personalized answers. Asking via a social network was also found to provide valuable confirmation of results found via a search engine.

Online social media can therefore serve as excellent information searching and browsing platforms that enable the sharing and communication of ideas, linking to professional groups of interest and creating online communities of practice. The increased popularity of online social communication/networking websites such as Facebook, Twitter and LinkedIn, has thus introduced a new dimension of finding information on the Internet, which may involve regular monitoring, browsing (for example, online topic discussions and community tags and ranked information) and/or actively seeking answers to specific information needs (via posing particular questions to online social networks of interest).

Finally, searching on online social media can also lead to serendipitous information discovery. A large part of everyday information seeking is based on different social networks of everyday life (we may call these interpersonal sources), and social media play a role in helping people to manage and extend these networks that become valuable and effective information channels. Searching and finding information is therefore made easier if someone within the online network has the knowledge that is being sought.

\section{Makerspaces and gamification}

As well as using IT Utilities to transform and enhance existing services, some libraries are also embracing technologies to facilitate new forms of knowledge creation leading to the development of makerspaces. According to Roslund and Rodgers (2014), a makerspace can be defined as:

Makerspace is a general term for a place where people get together to make things. Markerspaces might focus on electronics, robotics, woodworking, sewing, laser cutting, programming or some combination of these skills. (Roslund and Rodgers, 2014)

This suitably broad definition is reflective of the fact that makerspaces are heterogeneous and vary widely in their use and implementation within library spaces. It is important to note that while some technologies are mentioned in the definition, technology is not an essential component of the makerspace. Instead, the focus is on creation and sharing of knowledge and skills. Makerspaces can be, however, viewed as opportunities for democratizing new technologies such as $3 \mathrm{D}$ printing. While the costs of $3 \mathrm{D}$ printers have come down considerably in recent years they are still expensive to buy and maintain, and so they are not usually found around the home. Having a $3 \mathrm{D}$ printer in a makerspace is seen as being a big draw because they allow 
institutions such as libraries to fulfil their missions of being an equalizing force for knowledge and information, and to provide innovative ways for engaging with users that go beyond the "traditional" activities associated with libraries.

The concept of "gamification" as a tool to enhance user engagement and learning has also become increasingly popular. Gamification can be defined as "the use of game design elements in non-game contexts" (Deterding et al., 2013: 1). Gamification can include competitions, activities, creativity and learning, and are designed to add value to user experiences. Nicholson (2013) draws attention to the fact that during the Great Depression, libraries organized puzzle contests and circulated games and toys, and academic and school libraries have had a long tradition of developing game-based learning activities to help students and teachers. The difference now, according to Nicholson (2013) is that a generation of people who grew up with video games and are therefore "game literate" have now become adults and have differing expectations about what gaming in the library should look like. Gaming in the library can take a number of forms. At the most basic level libraries can build up games for users to borrow or rent. Special libraries exist for game collections such as at the University of Michigan. Users can be encouraged to engage in gaming activities for work or social learning activities or hobbies (for example, "serious gaming"), including those that they do not normally engage with and some libraries offer services to help patrons develop their own games.

The use of gaming and gamification for more formal learning purposes is somewhat contested. For example, taking a positive perspective, Charsky and Ressler (2011) argues that games can stimulate higher order thinking and can be engaging and motivational, as well as providing opportunities to provide additional instructions to aid learning. Ben-Zvi (2010) adds that games also aid the illustration of interrelationships between decision-making and outcomes, and can aid and enhance participatory learning and teaching. However, there are some who have reservations about potential negative consequences and repercussions of ill-thought out gamification initiatives. For example, Nicholson (2013) points out that reward-based gaming systems, such as earning badges and points for completing learning tasks or activities can actually have a negative impact because "Research shows that if someone does something for a reward, then their intrinsic motivation to do that thing decreases; therefore, if the reward is later removed, the drive for the person to do that thing is lower than before the rewards were put in place".

\section{The value of digital literacy within the context of academic libraries}

Within the expanding digital information arena, digital literacy is a highly sought competency among librarians, as library services are now offered through a range of media, including social network sites, mobiles phones or even virtual words. With the ubiquitous availability of digital information in different media forms and the ease of searching on the Web, with the advent of search engines such as Google and Bing, library staff are also expected to constantly remain up-to-date with different approaches followed for sourcing, creating and sharing information that are not necessarily supported within the formal academic environment and should reach out to students in more direct and meaningful ways. Paradoxically, within the era of digital information culture and connectivity (as digital information is growing with a rapid rate and becomes even more easily accessible and discoverable via less controlled routes) the more libraries connect directly with students the more students seem to disconnect from libraries. For example, students carry their knowledge structures, heuristics and tools that they use within their everyday life environments and transfer them to their academic studies without always an appreciation of the library services and their impact on their learning. Within the changing information arena, simplistic methods for searching and browsing beyond taught, "more sophisticated" library skills appear to be dominant. A report of findings from 2,318 respondents to a survey carried out among students across the United States found that students, rather than leveraging the wide range of resources available to them in the digital age and via the library, they instead employed a consistent and predictable research strategy for finding information, utilizing course readings and Google as a first port of call for course-related research (Head and Eisenberg, 2009).

There have been many studies examining the characteristics of the Google generation on the basis of less sophisticated and surface information seeking strategies, yet these are not necessarily evident only in younger generations. For example as Brewer (2002) has commented, "search engines have become a part of the global culture, reaching a vast and diverse audience" and not only younger populations. This also extends to the way in which people read and use information. For instance, online reading has been characterized in multiple studies to be shallow not only among younger populations (Liu, 2006), as time is spent on browsing and scanning than on focused reading of texts. The use of digital libraries by scholars has been described as bouncing, "squirrelling" or "power browsing" (Nicholas et al., 2010), a form of intensively focused search and collection of resources for later use. In sciences, the central unit of information has changed from a journal to an individual article because of the possibility of accessing articles directly in digital libraries (Tenopir et al., 2009). The Google generation study (Rowlands et al., 2008) demonstrated that we are all exposed to search engines and social media, and thus a part of the Google generation. Prensky (2009) proposed the notion of "digital wisdom", an enhanced state of being wise with the help of digital technology. The focal aspect of the proposition is that a departure from traditional ways of searching, reading and communicating is prominent. However, this may not necessarily mean that these new practices are to be avoided or that they are inferior. For example, using new generation reader devices may mean successfully combining the flexibility of digitality with many of the qualities of printed books and not that reading has been overall reduced. Using search engines for sourcing information many mean discovering new intelligent methods for information discovery and retrieval and not necessarily utilizing information that is not academic or of low quality. Considering this in relation to the academic librarianship domain, these changes signify the need for addressing new models of information service provision across the spectrum and critically reflecting up what these changes mean for academic librarians and their own practices.

Library staff roles have thus evolved and there is more emphasis on the importance of staying current with new media and digital trends, as well as modern approaches to information seeking and use, sharing and communication. The role of the information professional is viewed as shifting from being a custodian or gatekeeper to that of a facilitator or mediator of information (Currall and Moss, 2008). Traditional librarianship competencies coupled with, among others, technology and instructional design skills are essential for library jobs that deal with instruction of users and specialist roles have been created to reflect this trend, such as learning developers, learning technologists and skills managers. However, we also see an increasing demand for the development of other transferable skills, such as teaching and instruction with references to new media and ways of learning (for example, online, blended), which have become of 
paramount importance within the academic library context. For instance one of the concerns is whether library staff are aware of educational theories when teaching information literacy, the lack of which could potentially have a negative impact on learning outcomes. Library staff face challenges in the areas of teaching and particularly in terms of following established pedagogical and teaching models that are required in the effective development of library users' development of information literacy skills.

\section{Empowering academic librarians}

The embedded or blended academic librarianship approach is based on establishing a partnership between academics and librarians, placing the librarians at the centre of the learning process and making them active participants in the process of teaching, learning and assessment (Shumaker and Tyler, 2007; Shank and Bell, 2011. The blended librarian participates actively and holistically in students' learning, developing an essential skill set that blurs the boundaries between traditional library competencies, information technology and instructional/educational design skills. In that way librarians can participate actively in the development of academic courses and ensure that the teaching of information literacy is embedded into the curriculum, work together with academics to prepare reading lists and offer consultancy and support in sourcing quality information in relation to specific subject areas. A number of fundamental qualities empower this role: leadership, commitment, collaboration, communication and engagement that are fundamental for creating partnerships between librarian and faculty (Bell and Shank, 2004). Although reaching beyond the academic context to address the wider organizational environment, the model of embedded librarianship carrying similar connotations with blended librarianship, is described as the physical movement of the work of librarians from a central library close to the customer groups of an organization. Embedded librarians offer a range of services, including training, research, current awareness and alerting services, assessing literature and managing web content, all of which require the development of information technology skills (Shumaker and Talley, 2009), but also other soft skills such as team work, collaboration and customer service. Within the context of academic library work specifically, this may involve support for open access (for example, Orchid profiles) and ensuring that work is included in the Institutional Repository with correct metadata, enabling easier citation tracking and analysis (bibliometrics) of academics' research work and helping them prepare for the requirements of the REF. A further area where librarians can assist research is by encouraging and supporting researchers to utilize research focussed social media platforms such as ResearchGate, Google Scholar and Academia. edu, and organizing platforms such as Mendelay and RefMe. This model of blended/embedded librarianship deliberately moves librarians away from the physical space of the library, creating new and less predictable opportunities but also challenges. Schumacher, offers a number of examples that offer evidence around the value of physical collocation, demonstrating the higher level of engagement and contribution possible when librarians work as part of a unit, a community/group, as part of the whole and how librarians' roles transform into team-based expert roles that involve partnership around value-added research and information curation activities (Shumaker, 2012).

Therefore, information skills instruction may require a better understanding of students' contemporary information practices in everyday life and how this affects their approaches to academic information sources. Furthermore, it creates new roles for academic libraries in terms of advocating the development of information literacy in students and following more collaborative approaches with academics that will enable them to highlight its value by incorporating it within the learning objectives of different courses. This also means that libraries need to keep up-to-date with current research in the area of information literacy and develop more embedded relationships with academic staff.

\section{Conclusion}

This article has presented an overview of some of the key areas where IT Utilities are influencing the academic library sector. In particular, academic libraries have demonstrated tremendous adaptability for serving the needs of a larger and more diverse student body (including developments in distance and blended learning) and services are now much more user-driven and tailored in response to the demands of 24-7 access to resources across a wide variety of platforms. Furthermore, academic libraries have also played a key role in the implementation and governance of open access mandates and enabled researchers to widen the reach of their research by the management of institutional repositories and data management. Future demands from users for personalized services and requirements from external funding bodies to demonstrate impact and value for money from academic research will likely lead to further challenges and opportunities for libraries.

As indicated in the article the staffing profile of academic libraries has shifted away from "traditional" academic librarianship roles to a more diverse range of roles including nonprofessional library assistants, teaching and learning assistants, and specialist "blended" or academic liaison roles. This change, may be perceived by some, as being at odds with the traditional notion of the librarian as the gatekeeper of information and knowledge as it calls for a wider level transition that positions academic librarians beyond the restriction of their physical space and resources, to seek opportunities for continuing learning and development via active collaboration and partnerships, and develop a vision that fosters a learning culture for staff beyond the walls of the library (Martzoukou, 2013). Training for new library staff (such as postgraduate library and information management courses) must reflect these new roles and demands as well as making available continuous professional development opportunities for existing professionals. The Chartered Institute of Library and Information Professionals in the U.K. places emphasis on expanding the development of skills beyond traditional library skills in their Professional Knowledge and Skills Base to embrace the depth and breadth of professional, technical knowledge and transferable skills that can be used as a tool for professional development and as a framework for skills analysis, staff training and development plans beyond the domain of librarianship. It is clear that in order for the potential of IT Utilities to be fully realised that additional support needs to be made available to libraries in terms of funding, partnerships with businesses and training and skills development for staff. As academic librarians are called to assert their roles in a changing technological and blended learning environments there is a need for a wider exchange of information and collaboration with other professional groups, both academic and support staff who can provide their expertise on technology and educational/instructional design. The positioning of the academic library within professional support services of universities in the United Kingdom rather than as an academic function may mean that organizational boundaries between academic and non-academic staff may be a barrier to these developments.

A lot of new IT Utility equipment and services are specialised and, while costs and barriers to entry are reducing, there is still an uneven take up of new technologies and more specialised 
activities. This is particularly the case for libraries outside of major metropolitan areas or in less developed countries. There are further challenges of procurement and maintenance of specialist equipment-beyond the initial outlay there are also costs associated with maintaining equipment, which can be prohibitive. These challenges could be overcome in part by new business models for shared services between institutions and joint working between the library and academic IT services. There should also be rigorous impact assessments conducted of IT Utilities in libraries to assist with benchmarking and to determine recommendations and best practice guidelines to assist with knowledge transfer between institutions. Further, while new academic libraries are being purpose built with collaboration spaces and designed to have activity areas, many libraries, do not have the physical space to host specialist equipment or run workshops or the spaces may not be suitable for the purposes. Academic libraries have not been as strongly hit by cuts to public services as has been evident in other library sectors in the United Kingdom. However, academic library services still need to compete for resources with other departments and must be prepared to justify their spending and demonstrate value in an increasingly market-oriented HE landscapes, and it may also be necessary for libraries to review their service priorities divest from certain activities if required.

Within the fast changing environment of academia, there are not only new emerging roles for academic library staff (for example, research and data management), but also traditional roles (for example, information literacy instruction) that have evolved with greater demands placed on technological, interpersonal, IT and transferable skills. The development of subject domain expertise within multidisciplinary research fields, and the world of academic information has become increasingly more complex with open access, big data, and new models of online learning, teaching and research (for example, blended learning, online research) will likely lead to further challenges and opportunities in future. As shown throughout the article, academic libraries have consistently demonstrated the capacity to adapt and change to meet the needs of users, which is reflected in the new user-centred approach to service delivery.

\section{References}

Applegate R (2009) The library is for studying: Student preferences for study space. The Journal of Academic Librarianship; 35 (4): 341-346.

Arts Council England (2013) Envisioning the library of the future phases 1 and 2: Full report. Arts Council England: London.

Arte A and Cassella M (2014) Survey on Open Access collection development and management: a comparison analysis between Italy and UK. Paper presented at IFLA WLIC 2014, 16-22 August, Lyon, France, http://library.ifla.org/845/1/108arte_en.pdf, accessed 17 June 2016.

Bell SJ and Shank J (2004) The blended librarian a blueprint for redefining the teaching and learning role of academic librarians. College \& Research Libraries News; 65 (7): 372-375.

Ben-Zvi T (2010) The efficacy of business simulation games in creating decision support systems: An experimental investigation. Decision Support Systems; 49 (1): 61-69.

Berube L (2011) Do You Web 2.0?: Public Libraries and Social Networking. Chandos Publishing: Oxford.

Bilandzic M and Johnson D (2013) Hybrid placemaking in the library: Designing digital technology to enhance users' on-site experience. The Australian Library Journal; 62 (4): 258-271.

Brewer EA (2002) The consumer side of search". Communications of the ACM; 45 (9): 40-41.

Cameron C and Siddall G (2015) Academic staff perceptions and use of reading lists for book ordering. SCONUL Focus; 64, 41-44.

Charsky D and Ressler W (2011) "Games are made for fun": Lessons on the effects of concept maps in the classroom use of computer games. Computers \& Education; 56 (3): 604-615.
Christiansen L, Stombler M and Thaxton L (2004) A report on librarian-faculty relations from a sociological perspective. The Journal of Academic Librarianship; 30 (2): 116-121.

Chu SK and Du HS (2013) Social networking tools for academic libraries. Journal of Librarianship and Information Science; 45 (1): 64-75.

Clark C and Hawkins L (2010) Young People's Reading: The Importance of the Home Environment and Family Support. More Findings from Our National Survey. National Literacy Trust, http://eric.ed.gov/?id = ED510272, accessed 17 June 2016.

Cox AM and Pinfield S (2014) Research data management and libraries: Current activities and future priorities. Journal of Librarianship and Information Science; 46 (4): 299-316.

Creed-Dikeogu G and Clark C (2013) Are you MOOC-ing yet? A review for academic libraries. Kansas Library Association College and University Libraries Section Proceedings; 3 (1): 9-13.

Currall J and Moss M (2008) We are archivists, but are we OK? Records Management Journal; 18 (1): 69-91.

Davidson J, Jones S and Molloy L (2014) Big data: the potential role of research data management and research data registries. In: IFLA World Library and Information Congress 80th IFLA General Conference and Assembly, Lyon, France, 16-22 August, http://eprints.gla.ac.uk/102160/, accessed 17 June 2016.

Datig I (2015) Walking in your users' shoes: an introduction to user experience research as a tool for developing user-centered libraries. College \& Undergraduate Libraries; 22 (3-4): 234-246.

De Castro P, Shearer K and Summann F (2014) The gradual merging of repository and CRIS solutions to meet institutional research information management requirements. Procedia Computer Science; 33, 39-46.

Deterding S, Björk SL, Nacke LE, Dixon D and Lawley E (2013) Designing gamification: creating gameful and playful experiences, CHI'13 extended abstracts on human factors in computing systems, ACM, 3263,http://dl.acm. org/citation.cfm?id =2479662, accessed 17 June 2016 .

Fjällbrant N (1997) Scholarly communication-historical development and new possibilities. IATUL Conference Proceedings, Norwegian University of Science and Technology, 30 June-4th July, http://www.iatul.org/conference/proceed ings/vol07/papers/full/nfpaper.html, accessed 07 March 2016.

Gilmour R and Sapp G (2002) A brief history of the future of academic libraries: predictions and speculations from the literature of the profession, 1975 to 2000 - part one, 1975 to 1989, portal. Libraries and the Academy; 2 (4): 553-576.

Gilmour R and Sapp G (2003) A brief history of the future of academic libraries: Predictions and speculations from the literature of the profession, 1975 to 2000 - part two, 1990 to 2000, portal. Libraries and the Academy; 3 (1): 13-34.

Hall M (2012) Green or gold? Open access after Finch. Insights; 25 (3): 235-240.

Head AJ and Eisenberg MB (2009) Finding context: what today's college students say about conducting research in the digital age. Project information literacy progress report. Project information literacy, http://files.eric.ed.gov/fulltext/ ED535161.pdf, accessed 07 March 2016.

Higher Education Funding Council for England. (2015) Policy for open access in the post-2014 Research Excellence Framework, http://www.hefce.ac.uk/pubs/ year/2014/201407/, accessed 07 March 2016

Houghton JW and Oppenheim C (2010) The economic implications of alternative publishing models. Prometheus; 28 (1): 41-54.

IT as a Utility Network+. (n.d.) About, http://www.itutility.ac.uk/what-is-it-as-autility-itaau/, accessed 17 March 2016.

Jacobs N, Thomas A and McGregor A (2008) Institutional repositories in the UK: the JISC approach. Library Trends; 57 (2): 124-141.

Kingsley DA and Kennan MA (2015) Open access: The whipping boy for problems in scholarly publishing. Communications of the Association for Information Systems; 37 (14), http://aisel.aisnet.org/cais/vol37/iss1/14, accessed 17 March 2016.

Liu Z (2006) Print vs. electronic resources: a study of user perceptions, preferences, and use. Information Processing \& Management; 42 (2): 583-592.

Martzoukou K (2013) Empowering information literacy and continuing professional development of librarians: New paradigms for learning. In: Kurbanoglu S, Grassian E, Mizrachi D, Catts, R and Špiranec S (eds). Proceedings of the European Conference on Information Literacy, ECIL 2013. Worldwide Commonalities and Challenges in Information Literacy Research and Practice, Springer: Istanbul, Turkey, 647-654.

Morris MR, Teevan J and Panovich K (2010) What do people ask their social networks, and why?: a survey study of status message q\&a behavior, in Proceedings of the SIGCHI Conference on Human Factors in Computing Systems, ACM: 1739 , http://131.107.65.14/en-us/um/people/merrie/papers/social_qna_ chi2010.pdf, accessed 17 June 2016.

National Literacy Trust. (2013) Children's on-screen reading overtakes reading in print, http://www.literacytrust.org.uk/media/5371_children_s_on-screen_read ing_overtakes_reading_in_print, accessed 07 March 2016.

Nicholas D, Rowlands I, Jubb M and Jamali HR (2010) The impact of the economic downturn on libraries: with special reference to university libraries. The Journal of Academic Librarianship; 36 (5): 376-382. 
Nicholson S (2013) Two paths to motivation through game design elements: reward-based gamification and meaningful gamification. iConference 2013 Proceedings, https://www.ideals.illinois.edu/bitstream/handle/2142/42082/313. pdf? sequence $=2$, accessed 17 June 2016 .

Paulus MJ (2011) Reconceptualizing academic libraries and archives. Libraries and the Academy; 11 (4): 939-952.

Prensky M (2009) H. sapiens digital: from digital immigrants and digital natives to digital wisdom. Innovate: Journal Of Online Education; 5 (3), http://nsuworks. nova.edu/innovate/vol5/iss3/1, accessed 17 June 2016.

Research Councils UK. (2015) Common principles on data management, http:// www.rcuk.ac.uk/research/datapolicy/, accessed 07 March 2016.

Roslund S and Rodgers EP (2014) Makerspaces. Cherry Lake Publishing: Ann Arbor, MI.

Rowlands I et al (2008) The Google generation: The information behaviour of the researcher of the future. Aslib Proceedings; 60 (4): 290-310.

SCONUL. (June 2015) Changing trends in loans, visits \& the use of e-books, http:// www.sconul.ac.uk/sites/default/files/documents/Analysis\%20_Loans\%20ebooks \%20visits\%20June\%202015.pdf, accessed 07 March 2016.

Shank JD and Bell S (2011) Blended librarianship. Reference \& User Services Quarterly; 51 (2): 105-110.

Shumaker D (2012) The Embedded Librarian: Innovative Strategies for Taking Knowledge Where it's Needed. Information Today: Medford, NJ.

Shumaker D and Talley M (2009) Models of embedded librarianship: Final report, Special Libraries Association 9, http://citeseerx.ist.psu.edu/viewdoc/download? doi $=10.1 .1 .679 .8208 \&$ rep $=$ rep1\&type $=$ pdf, accessed 07 March 2016.

Shumaker D and Tyler LA (2007) Embedded library services: an initial inquiry into practices for their development, management, and delivery. Paper presented at the Special Libraries Association Annual Conference, Denver, CO, 6 June, https://www.researchgate.net/publication/241197355_Embedded_Library_Ser vices_An_Initial_Inquiry_into_Practices_for_Their_Development_Manage ment_and_Delivery, accessed 17 June 2016 .

Stevens CR (2013) Reference reviewed and re-envisioned: revamping librarian and desk-centric services with LibStARs and LibAnswers. The Journal of Academic Librarianship; 39 (2): 202-214.

Swan A (2011) Institutional repositories-Now and next. In: Dale P, Beard J and Holland M (eds). University Libraries and Digital Learning Environments, Ashgate: Farnham, UK; pp 119-133.

Tenopir C, King DW, Edwards S and Wu L (2009) Electronic journals and changes in scholarly article seeking and reading patterns. Aslib proceedings; 61 (1): 5-32.
Walters WH (2013) E-books in academic libraries: challenges for acquisition and collection management, portal. Libraries and the Academy; 13 (2): $187-211$.

Weiner SG (2005) The history of academic libraries in the United States: a review of the literature. Library Philosophy and Practice; 7 (2): 1-12.

Weise F (2004) Being there: the library as place. Journal of the Medical Library Association; 92 (1): 6-13.

Whyte A and Tedds J (2011) Making the Case for Research Data Management (DCC Briefing Papers). Digital Curation Centre: Edinburgh, UK.

Wilder S (2005) Information literacy makes all the wrong assumptions. The Chronicle Review; 51 (18): 69-72.

\section{Data availability}

Data sharing not applicable to this article as no datasets were generated or analysed during the current study.

\section{Acknowledgements}

This work was funded by the IT as a Utility Network+ under the RCUK Digital Economy Programme. Grant reference: EP/K003569/1.

\section{Additional information}

Competing interests: The authors declare no competing financial interests.

Reprints and permission information is available at http://www.palgrave-journals.com/ pal/authors/rights_and_permissions.html

How to cite this article: Tait E et al. (2016) Libraries for the future: the role of IT utilities in the transformation of academic libraries. Palgrave Communications. 2:16070 doi: 10.1057/palcomms.2016.70

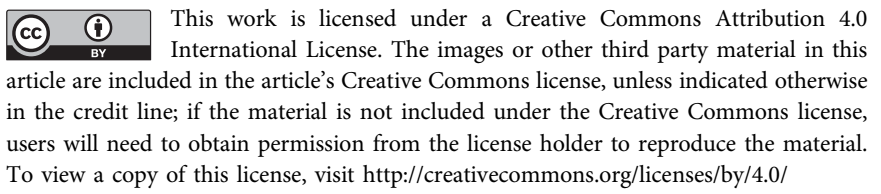

